\title{
CT imaging of two cases of one family cluster 2019 novel coronavirus (2019-nCoV) pneumonia: inconsistency between clinical symptoms amelioration and imaging sign progression
}

\author{
Xiaofei Hu ${ }^{1 \#}$, Jiafei Chen ${ }^{1 \#}$, Xiaomei Jiang ${ }^{2}$, Shiqi Tao ${ }^{3}$, Zhiming Zhen ${ }^{1}$, Chaoyang Zhou ${ }^{1}$, Jian Wang ${ }^{1}$ \\ ${ }^{1}$ Department of Radiology, Southwest Hospital, Third Military Medical University, Chongqing, 400038, China; ${ }^{2}$ Department of Centre for Disease \\ Prevention and Control, Chengdu Military Region, Chengdu, 610021, China; ${ }^{3}$ Department of Infectious Diseases, Southwest Hospital, Third \\ Military Medical University, Chongqing 400038, China
}

\#These authors contributed equally to this work.

Correspondence to: Jian Wang. Department of Radiology, Southwest Hospital, Third Military Medical University, Gaotanyan Street, Chongqing 400038, China. Email: wangjian811@gmail.com.

Submitted Feb 08, 2020. Accepted for publication Feb 12, 2020.

doi: 10.21037/qims.2020.02.10

View this article at: http://dx.doi.org/10.21037/qims.2020.02.10

\section{Introduction}

The emergence and spread of a novel coronavirus (2019$\mathrm{nCoV}$ ) from Wuhan City, Hubei Province of China, has become a global health concern (1). Since the detection of the coronavirus in late December 2019, sporadic imported cases among travelers returning from Wuhan and humanto-human transmission have been reported in several nonWuhan/non-Hubei areas $(2,3)$. We describe the CT features of one family cluster of 2019-nCoV.

\section{Case presentation}

A 47-year-old man presented to the hospital with a 2-day history of fever and cough, 6-day history of sneezing, runny and chills for unknown cause. He indicated that he worked in Wuhan, China and had not been exposed to the seafood and live animal market in Wuhan, where has been identified as the centre of the outbreak. He reported that he came to Chongqing On January 16 and lived with his wife for 10 days.

At admission, his body temperature was $37.0^{\circ} \mathrm{C}\left(98.6^{\circ} \mathrm{F}\right)$. Normal breath sounds of both lungs were heard at auscultation. Laboratory studies showed lymphopenia (lymphocyte count: $0.87 \times 10^{9} / \mathrm{L}$ ). There were elevated blood levels for C-reactive protein $(8.30 \mathrm{mg} / \mathrm{L}$; normal range, $0-8 \mathrm{mg} / \mathrm{L})$, erythrocyte sedimentation rate $(8.00 \mathrm{~mm} / \mathrm{h}$; normal range, $<20 \mathrm{~mm} / \mathrm{h})$, and $\mathrm{D}$-dimer (0.06 mg/L; normal range, $0-0.05 \mathrm{mg} / \mathrm{L})$. Unenhanced chest CT showed multiple consolidative peripheral opacities with ground-glass density in right upper lobe (Figure 1A) with a peripheral distribution, which has been reported as a common finding of $2019-\mathrm{nCoV}$ pneumonia $(2,4-6)$. A nasopharyngeal swab and sputum samples was positive for 2019-nCoV with the real-time reverse transcription polymerase chain reaction assay. After receiving 2 days of treatment, including the administration of combined interferon inhalation, oseltamivir and lopinavir/ritonavir, the patient reported symptoms relief. However, repeat chest CT showed progressive pulmonary opacities (Figure 1B).

The above patient's wife, a 38-year-old woman, presented to the hospital because of abdominal pain and diarrhea for 5 days; and headache, fever, and muscle soreness for 2 days, just on the same day when her husband presented to the hospital. She reported that she had not travel to Wuhan over the last year and had history of hepatitis B virus (HBV) infection for 20 years.

At admission, her body temperature was $37.3^{\circ} \mathrm{C}\left(99.14^{\circ} \mathrm{F}\right)$ and normal breath sounds of both lungs were heard at auscultation. Laboratory studies showed leucopenia (white blood cell count: $3.07 \times 10^{9} / \mathrm{L}$ ), lymphopenia (lymphocyte 

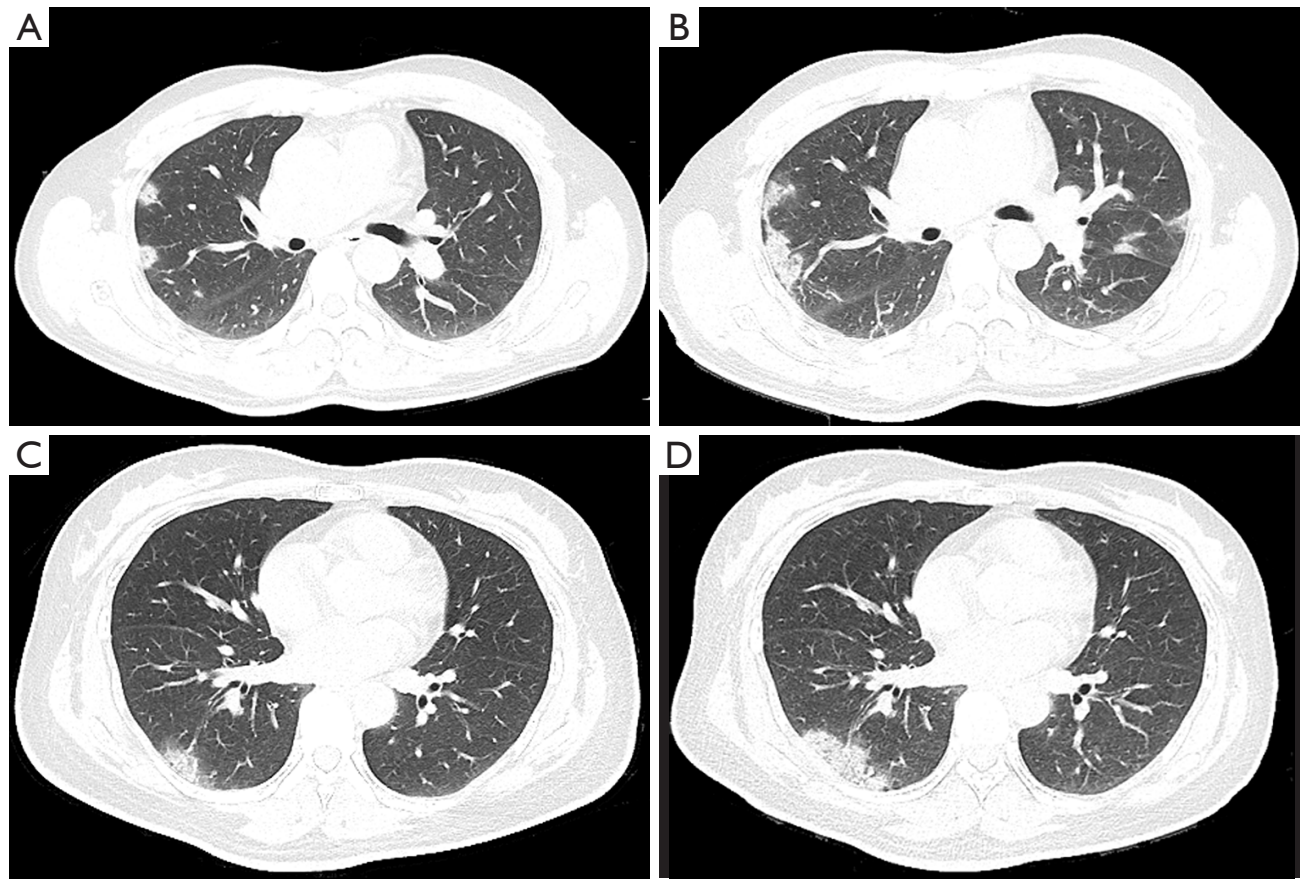

Figure 1 CT of two cases of One Family Cluster 2019 Novel Coronavirus (2019-nCoV) Pneumonia. (A,B) Unenhanced CT images of a 47-year-old man. (A) Image shows multiple consolidative peripheral opacities with ground-glass density in right upper lobe; (B) image obtained 2 days after (A) shows progressive consolidative peripheral opacities in the bilateral upper lobe. (C,D) Unenhanced CT images of a 38-year-old woman. (C) Image shows solitary consolidative peripheral opacities with ground-glass density in right lower lobe; (D) image obtained 2 days after (C) shows progressive consolidative peripheral opacities in right lower lobe.

count: $0.81 \times 10^{9} / \mathrm{L}$ ) and neutropenia (neutrophil count: $1.73 \times 10^{9} / \mathrm{L}$ ). There were elevated blood levels for C-reactive protein $(9.14 \mathrm{mg} / \mathrm{L}$; normal range, $0-8 \mathrm{mg} / \mathrm{L})$, erythrocyte sedimentation rate $(13 \mathrm{~mm} / \mathrm{h}$; normal range, $<20 \mathrm{~mm} / \mathrm{h})$, and D-dimer $(0.27 \mathrm{mg} / \mathrm{L}$; normal range, $0-0.005 \mathrm{mg} / \mathrm{L})$. Unenhanced chest CT showed solitary consolidative peripheral opacities with ground-glass density in right lower lobe (Figure 1C) with a peripheral distribution. Realtime fluorescence polymerase chain reaction of the patient's nasopharyngeal swab and sputum samples were positive for the 2019 novel coronavirus (2019-nCoV) nucleic acid. After the diagnosis of 2019-nCoV pneumonia was made, patient was immediately isolated for clinical monitoring and treatment. The patient also received therapy of interferon inhalation, oseltamivir and lopinavir/ritonavir for 2 days, and reported the symptoms relief, but with progressive pulmonary opacities found on repeat chest CT (Figure 1D).

\section{Discussion}

Although the diagnosis of 2019-nCoV must be based on etiologic test result, chest radiography is one of the major diagnostic components and plays a crucial role in the rapid identification and early diagnosis according to World Health Organization and CDC guidelines (7). It is crucial to summarize the most common and typical radiological findings of 2019-nCoV pneumonia.

The two cases both showed consolidative peripheral opacities with ground-glass density, which has been noted as the most common find of 2019-nCoV pneumonia (4-6). The lesions of the two cases were all subpleural, which is the typical distribution according to other reported studies (4-6). The literature reported that a high likelihood of this type of pneumonia affecting two lobes with bilateral involvement (4-6), which is in line with the husband's CT finding. But the wife's lesion affected only one lobe with unilateral solitary involvement. After 2-day antiviral treatment, the two cases both demonstrated symptom relief but progression on CT, which indicates that clinical symptoms and imaging findings are inconsistent in early-stage of 2019-nCoV-infected pneumonia. 


\section{Acknowledgments}

Funding: This work was supported by the National Nature Science Foundation of China (No. 81701664) and the Technology Innovation Program in Southwest Hospital (SWH2016JCYB-30).

\section{Footnote}

Conflicts of Interest: The authors have no conflicts of interest to declare.

Ethical Statement: Ethical approval was granted from the local ethics committee, and informed consent was obtained from participants.

\section{References}

1. Zhu N, Zhang D, Wang W, Li X, Yang B, Song J, Zhao X, Huang B, Shi W, Lu R, Niu P, Zhan F, Ma X, Wang D, Xu W, Wu G, Gao GF, Tan W; China Novel Coronavirus Investigating and Research Team. A Novel Coronavirus from Patients with Pneumonia in China, 2019. N Engl J Med 2020. doi: 10.1056/NEJMoa2001017. [Epub ahead of print]

2. Huang C, Wang Y, Li X, Ren L, Zhao J, Hu Y, Zhang L, Fan G, Xu J, Gu X, Cheng Z, Yu T, Xia J, Wei Y, Wu W, Xie X, Yin W, Li H, Liu M, Xiao Y, Gao H, Guo L, Xie J, Wang G, Jiang R, Gao Z, Jin Q, Wang J, Cao B. Clinical

Cite this article as: $\mathrm{Hu} \mathrm{X}$, Chen J, Jiang $\mathrm{X}$, Tao S, Zhen Z, Zhou C, Wang J. CT imaging of two cases of one family cluster 2019 novel coronavirus (2019-nCoV) pneumonia: inconsistency between clinical symptoms amelioration and imaging sign progression. Quant Imaging Med Surg 2020;10(2):508-510. doi: 10.21037/qims.2020.02.10 features of patients infected with 2019 novel coronavirus in Wuhan, China. Lancet 2020. doi: 10.1016/S01406736(20)30183-5. [Epub ahead of print]

3. Chan JF, Yuan S, Kok KH, To KK, Chu H, Yang J, Xing F, Liu J, Yip CC, Poon RW, Tsoi HW, Lo SK, Chan KH, Poon VK, Chan WM, Ip JD, Cai JP, Cheng VC, Chen H, Hui CK, Yuen KY. A familial cluster of pneumonia associated with the 2019 novel coronavirus indicating person-to-person transmission: a study of a family cluster. Lancet 2020. doi: 10.1016/S0140-6736(20)30154-9. [Epub ahead of print]

4. Lei J, Li J, Li X, Qi X. CT Imaging of the 2019 Novel Coronavirus (2019-nCoV) Pneumonia. Radiology 2020. doi: 10.1148/radiol.2020200236. [Epub ahead of print]

5. Kanne JP. Chest CT Findings in 2019 Novel Coronavirus (2019-nCoV) Infections from Wuhan, China: Key Points for the Radiologist. Radiology. 2020 Feb 4:200241. doi: 10.1148/radiol.2020200241. [Epub ahead of print]

6. Liu P, Tan XZ. 2019 Novel Coronavirus (2019nCoV) Pneumonia. Radiology 2020. doi: 10.1148/ radiol.2020200257. [Epub ahead of print]

7. General Office of National Health Committee. Office of State Administration of Traditional Chinese Medicine. Notice on the issuance of a programme for the diagnosis and treatment of novel coronavirus $(2019-\mathrm{nCoV})$ infected pneumonia (trial fifth edition) (2020-02-05). Available online: http://www.nhc.gov.cn/yzygj/s7653p/202002/3b09 b894ac9b4204a79db5b8912d4440.shtml 